\title{
OPTIMIZATION OF SUCTION GRIPPERS PLACEMENT FOR MANIPULATION WITH THIN CIRCULAR SHEET METAL
}

\author{
HAJDU, S[tefan]
}

\begin{abstract}
The article deals with finding optimal placement of the suction grippers on the area of circular sheet metal. The objective is to find a position of the suction grippers which ensures minimal deflection of this sheet metal. To find suitable position of the suction grippers was used worldwide known code CATIA V5. Through structural analysis and optimization methods of this robust software solution was found optimal location of the suction grippers. In this case will be deflection of sheet metal minimal. Simulated annealing algoritmus was used for solve given problem.
\end{abstract}

Keywords:Optimization, FEM, CATIA, Simulation model, Manipulation, Sheet metal

\section{INTRODUCTION}

Numerical methods represent many years leading computational utility. Initially uninteresting finite element method (FEM) has today become one of the main computing resources not only in the engineering industry. Main advantage FEM is graphic interpretation often very abstract phenomena in which classical technique solutions introduces considerable simplification at the expense of accuracy.

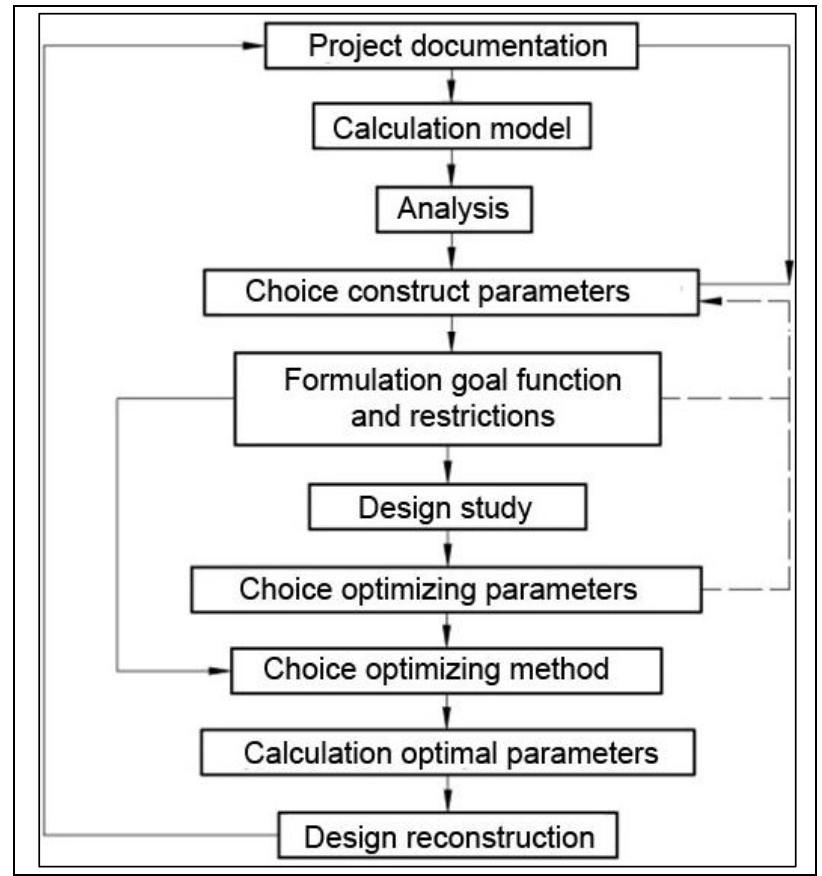

Fig. 1. Procedure for design optimization[1]

Problems of the optimal design dealt already Galileo (1638) who derived the shape fixed beam with constant normal stress. Although Galileo did not define an optimization problem his results was confirmed with modern approaches. Development of optimization is mainly conditioned by the limited energy and material resources, strong competition and recently the problems of environmental protection.

\section{THEORETICAL BASE}

Optimization can be defined as the procedure for obtaining the design, which is best of all possible proposals with regard to the prescribed objective and a given set of geometric boundaries of the system behavior. This objective is of great technical significance [2] and [3].

Optimization is a type of design problem where a set of design parameters is divided into two groups. The first group consists of predefined parameters. The second group consists of parameters called design variables. Optimization then we understand finding the optimal values of design variables to maximize the objective or criterial function whereby must meet requirements (called boundaries) on the geometry and state structures. CATIA V5 software contains several algorithms for optimization. One of them is the simulated annealing algorithm. This optimization method can be viewed as an extension of gradient method, which prevents sticking to solve[4] and [5].

Simulated annealing is a computational stochastic technique for obtaining near global optimum solutions to combinatorial and function optimization problems. The key principle of the method is to allow occasional worsening moves so that these can eventually help locate the neighborhood to the true (global) minimum [6].

\section{SIMULATION MODEL}

The simulation model was created in CAD $\backslash C A M \backslash C A E$ system CATIA V5. The cirkular sheet metal with dimensions from $\varnothing 700 \times 0.5 \mathrm{~mm}$ to $\varnothing 1300 \times 0.5 \mathrm{~mm}$ (step for diameter $100 \mathrm{~mm}$ ) were idealized through shell type elements named QD8 (parabolic) with representation of sheet metal thickness $0.5 \mathrm{~mm}$. Consider for the demonstration of the case study the circular plate with dimensions $\varnothing 1000 \times 0.5 \mathrm{~mm}$.

The following procedure was performed for all the above defined variations of circular plates.

I have considered four suction grippers with diameter $\varnothing \mathrm{e}=40 \mathrm{~mm}$. Generated mesh was from the most part consists of square mapped elements. Maximal size of the generated elements has been set to value $10 \mathrm{~mm}$. 


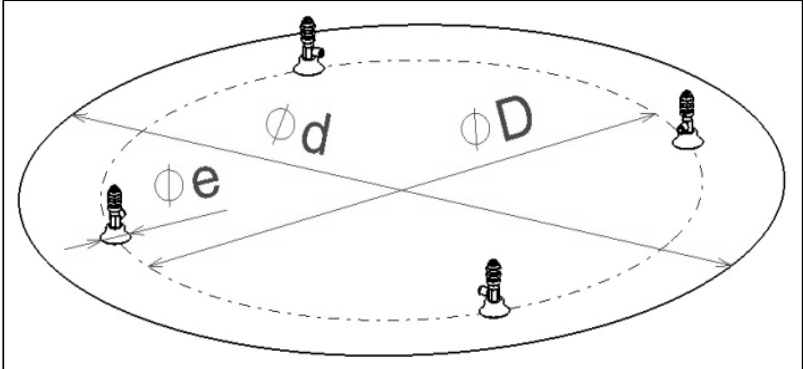

Fig. 2.Design of the assembly

Generated finite element mesh together with boundary conditions you can see on the Fig. 3. Mathematical formulation of the sheet metal clamping with suction grippers was simulated with the boundary condition which allowed deformation in the sheet metal in location of the clamping.

In the simulation model was considered $70 \%$ vacuum which also affects the deformation of thin sheet metal therefore was include into the CAE model through external load in form overpressure with the value $0.07 \mathrm{MPa}$. The breakaway force equals $69.6 \mathrm{~N}$ for suction grippers of the type ESG with diameter of $40 \mathrm{~mm}$ at $70 \%$ vacuum [7] and [8]. Sheet metal is bending mainly by gravitational acceleration whose value is $9.81 \mathrm{~m} . \mathrm{s}^{-2}$. Sheet metal part is made from low carbon steel STN 411373 (DIN 1.0036). Elasticity modulus of the steel is $210 \mathrm{GPa}$ and Poisson's ratio is 0.3. Density of the steel is $7800 \mathrm{~kg} \cdot \mathrm{m}^{-3}$. The resulting mass of the sheet metal is $3,063 \mathrm{~kg}$.
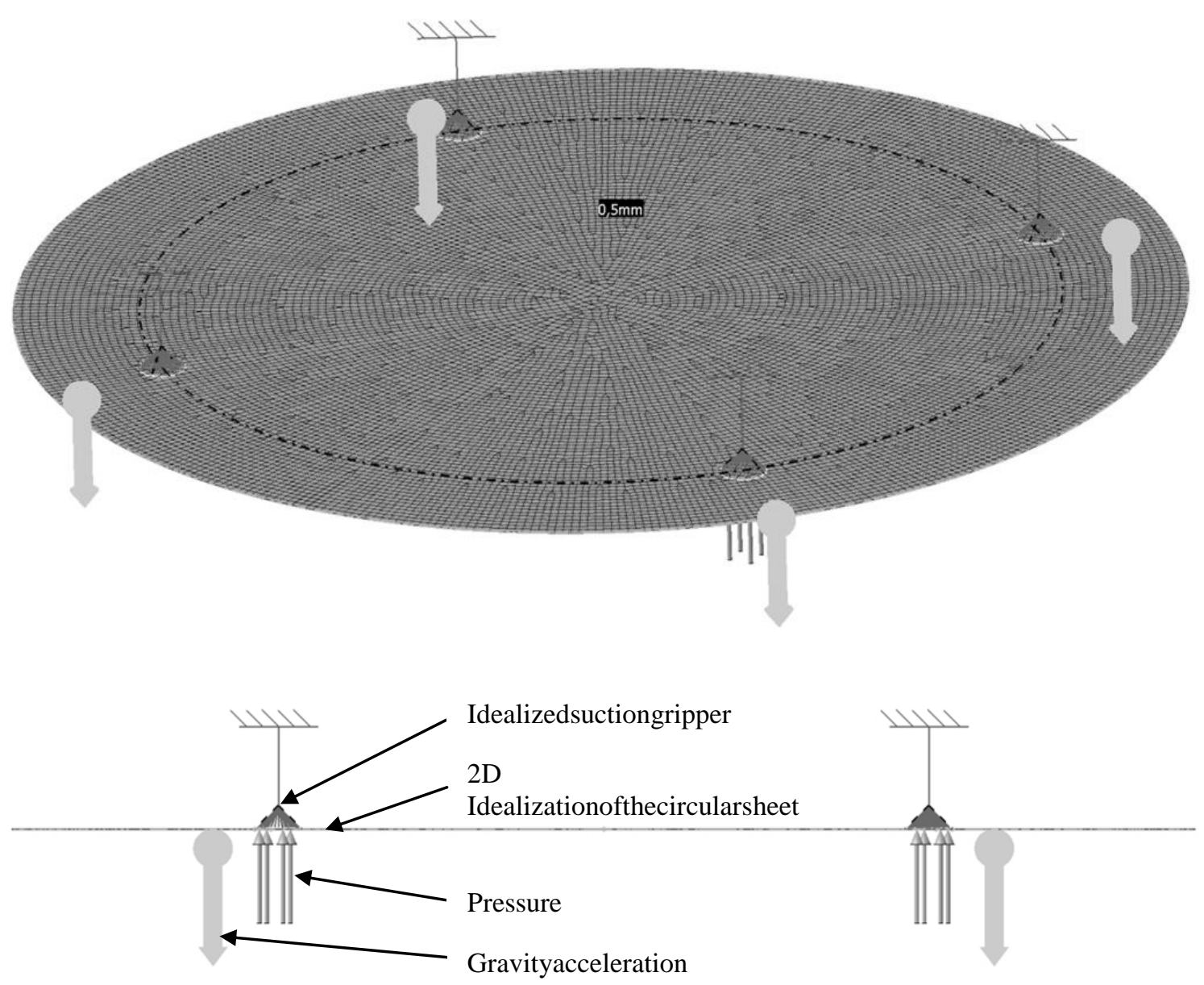

Fig. 3. Generated mesh with boundary conditions and external loads

The goal of the optimization was searching of the minimum value of maximum sheet metal deflection. Variable design parameter was (ØD) diameter of the pitch circle of suction grippers (see Fig. 2). C range of the variable parameter is presented in Tab. 1.

\begin{tabular}{|c|c|c|c|}
\hline Dimension & Initial (mm) & $\begin{array}{c}\text { Min } \\
(\mathbf{m m})\end{array}$ & Max (mm) \\
\hline$\varnothing D$ & 100 & 100 & 940 \\
\hline
\end{tabular}

Tab. 1. Initial value and range of the variable parameter

Simulated annealing optimization algorithm was set to unlimited time period. For searching optimal values of the variable parameters was algorithm limited only by the count of possible updates that could be made. Count of the updates was set on 100 .

\section{OBTAINED RESULTS}

Approximate dependence of the maximum displacement depending on the size of pitch circle diameter on which are placed at regular intervals vacuum effectors was obtained by sensitivity analysis. Range of the pitch circle diameter is from $100 \mathrm{~mm}$ to $940 \mathrm{~mm}$. Step was set to the value $10 \mathrm{~mm}$. Summary was executed 85 iterations. 
From the obtained results has been made graph which is shown in Fig. 4. Goal of the optimization is to find minimum of the function which is shown on Fig. 4. From the Fig. 4 is therefore clear that minimum displacement value will be found somewhere at around the value of the pitch circle diameter $780 \mathrm{~mm}$ for this example.

By finding the extreme objective function were obtained displacement values of the elements nodes for
100 different locations of the grippers. Process of the optimization can you see on Fig. 5. Minimal deflection was found in step 94 with a maximum value of local plate deformation $9.8193 \mathrm{~mm}$. Value of the pitch circle diameter of grippers is for found optimum following $\varnothing \mathrm{D}=785.8749 \mathrm{~mm}$.

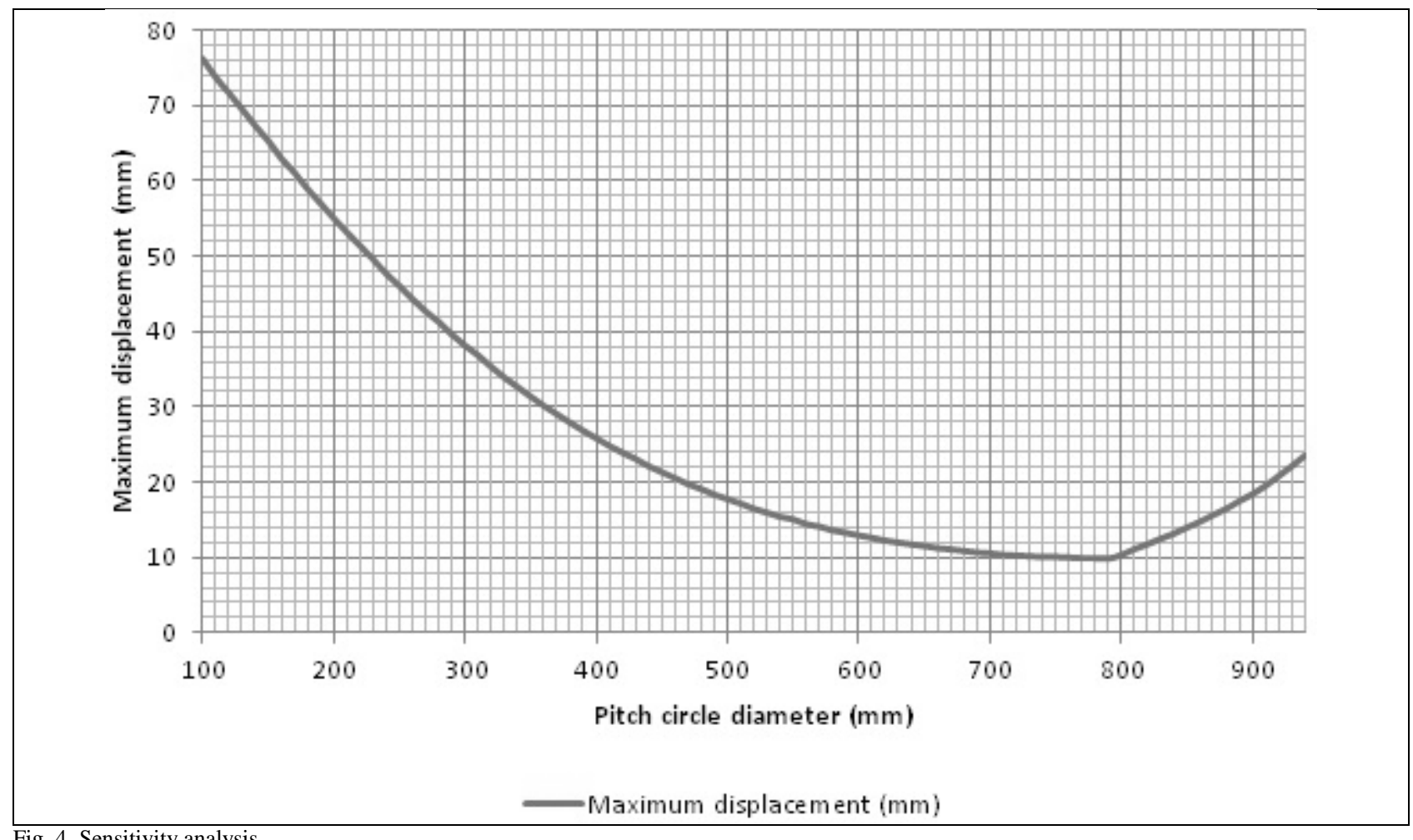

Fig. 4. Sensitivity analysis

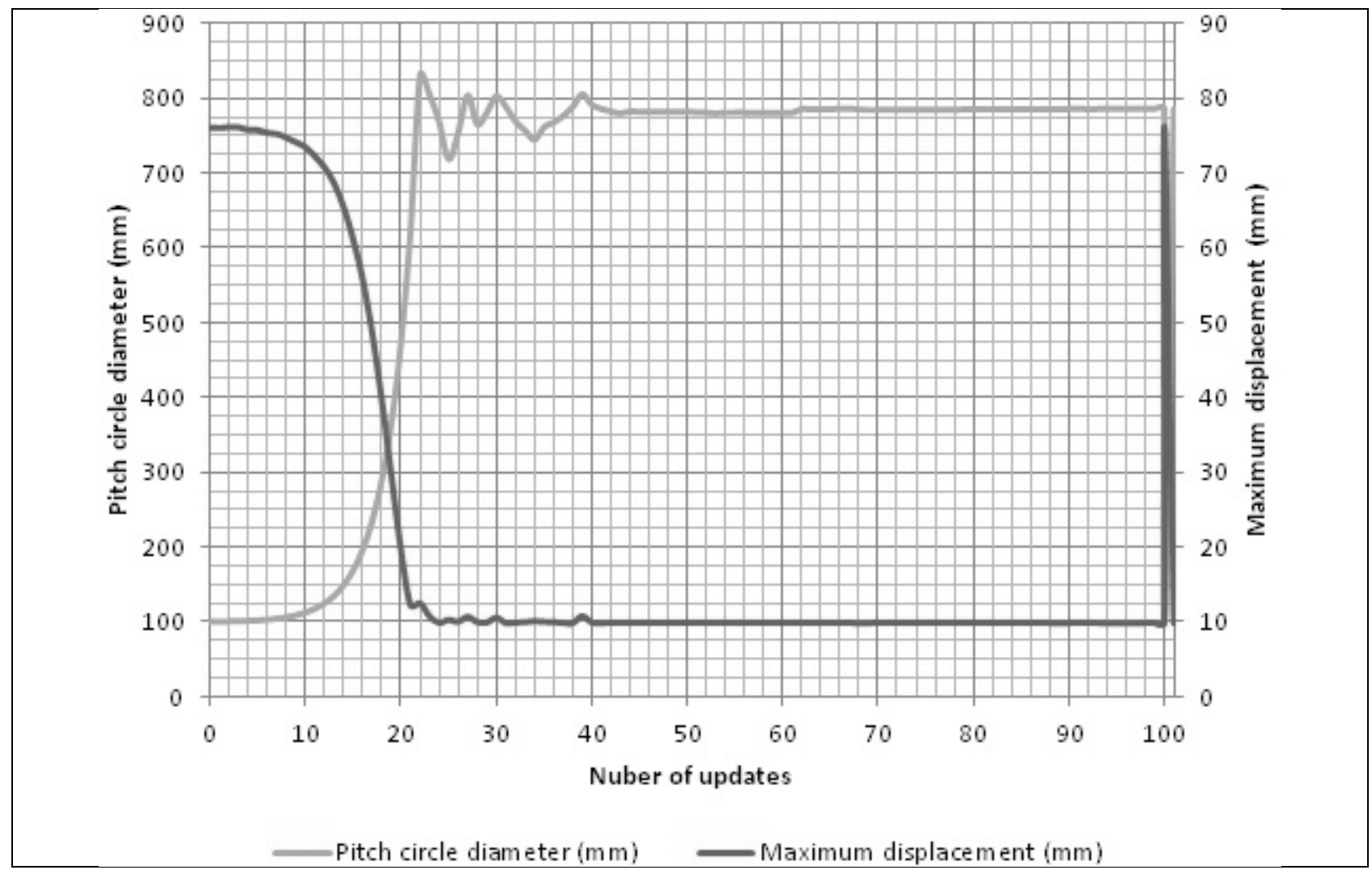

Fig. 5. Process optimization (simulated annealing algorithm) 
From the results of difficult optimization procedures revealed that the deflection of a circular sheet metal with dimensions from $\varnothing 700 \mathrm{~mm}$ to $\varnothing 1300 \mathrm{~mm}$ with material thickness $0.5 \mathrm{~mm}$ will be the smallest if will be four grippers situated for arbitrarily large circular sheet metal in a ratio ØD / Ød $=0.7851$. See the Tab. 2 .

\begin{tabular}{|c|c|c|}
\hline $\begin{array}{c}\text { Circular sheet metal } \\
\text { dimensions }(\mathbf{m m})\end{array}$ & $\begin{array}{c}\text { Optimal } \\
\text { diameter }(\mathbf{m m})\end{array}$ & $\begin{array}{c}\text { Optima } \\
\text { l ratio }\end{array}$ \\
\hline$\varnothing 700 \times 0.5$ & 552.1877 & 0.7888 \\
\hline$\varnothing 800 \times 0.5$ & 645.1857 & 0.8065 \\
\hline$\varnothing 900 \times 0.5$ & 710.9679 & 0.7900 \\
\hline$\varnothing 1000 \times 0.5$ & 785.8750 & 0.7859 \\
\hline$\varnothing 1100 \times 0.5$ & 847.4413 & 0.7704 \\
\hline$\varnothing 1200 \times 0.5$ & 932.8499 & 0.7774 \\
\hline$\varnothing 1300 \times 0.5$ & 1009.5110 & 0.7765 \\
\hline Average ratio value & & 0.7851 \\
\hline
\end{tabular}

Tab. 2. Initial value and range of the variable parameter

On the Fig. 6 and Fig.7 you can see stress and displacement results of the best solution obtained from the optimization process.Global maximum stress von Misses is achieved under vacuum effectors with value $153 \mathrm{MPa}$. The maximum deflection is $9.87 \mathrm{~mm}$. Maximum deflection is localized on the plate perimeter between vacuum effectors.

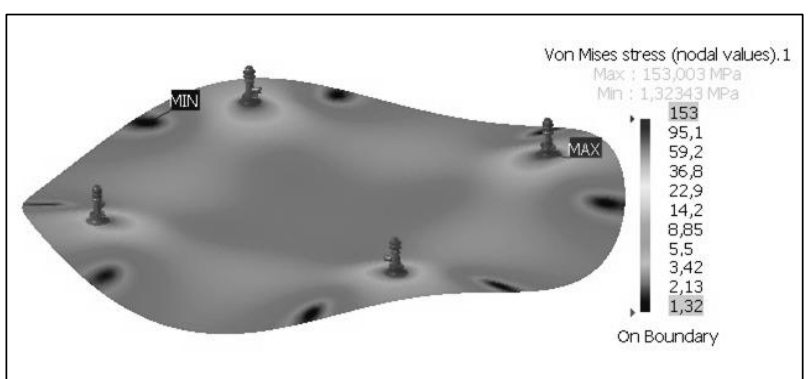

Fig. 6. Equivalent (von Misses) stresses (logarithmic legend)

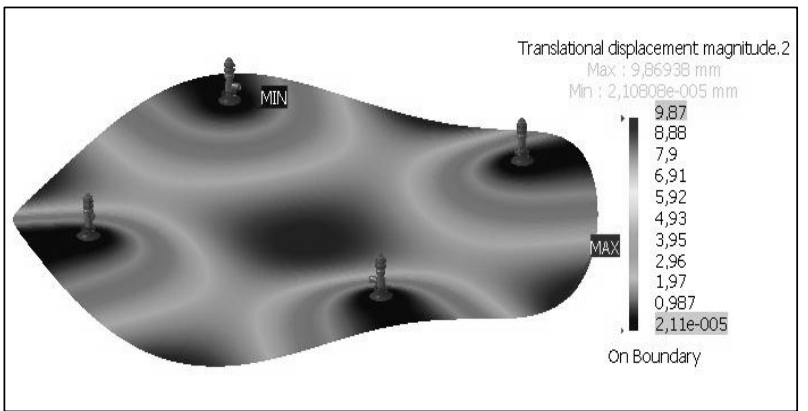

Fig. 7. Displacements (linear legend)

The obtained results can be applied for automatized handling devices which based on the evaluation of the diameter plate can adjust the optimal pitch circle diameter of clamping effectors so as to minimize the deflection of a circular plate.This optimal position of the effectors also applies to other materials such as glass, plastic, aluminum, brass, bronze, etc.

\section{DISCUSSION}

Through minimalization deflection of the sheet metal will be prevent a possible pull-off of the suction gripper from the sheet metal surface. This condition may occur even if the load does not exceed breakaway force of the suction gripper, but the curvature of the sheet metal will be too high. In the future I would like to deal with finding the optimal placement of suction grippers on the rectangular sheet metal and circular sheet metal which will be load with dynamic loading. Under dynamic loading will play an important role the inertial forces, therefore will be need to consider also the body weight of the sheet metal (material model have to contain density).In this way will possible to simulate and to find the response of sheet metal during handling respectively during motion.

\section{CONCLUSION}

By repeating of the optimization routines for circular shaped sheet metals with modified dimensions $(\varnothing 700 \times 0.5$--- $\varnothing 1300 \times 0.5)$ it was concluded that the placement of four suction grippers meet the minimum deflection sheet metal if these suction grippers will be placed on the pitch circular diameter $\varnothing \mathrm{D}=\varnothing \mathrm{d}$. (0.7851).

While respecting this condition is achieved also minimum load of the part with bending moment caused by self-weight of this part. Therefore by handling with the part in this optimized position with four suction grippers is least likely that clamped part will be degraded with the permanent deformations. This knowledge can be used wherever it is required clamping of the part with circular cross-section on the four supports to achieve minimal deflection of this clamped part.

\section{ACKNOWLEDGEMENTS}

This paper was realized with the support of grant VEGA 1/0389/11.

\section{REFERENCES}

[1] Sedlár, P. (2007). Evaluation and comparison of optimization methods in the design of the measuring equipment for agriculture, Slovak University of Agriculture in Nitra, PhD Thesis, p. 152

[2] Žmindák, M. et al. (2000). Optimization of mechanical systems, Žilina: EDIS, p. 261, ISBN 80 - 7100 - 631 - 9

[3] Hajdu, Š., Kučera, M. (2007). Optimization of mountain bike disk brake. In New trends in design and technical documentation creation 2007: Proceedings of scientific papers, Nitra: Slovak University of Agriculture in Nitra, 2007. p. 38-45. ISBN 978-80-8069-883-6

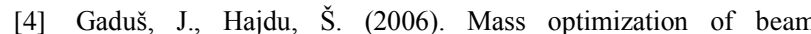
structures. In Acta mechanica Slovaca, č. 4-B, roč. 10, Košice: Faculty of Mechanical Engineering, The Technical University of Košice, 2006. p. 149-154. ISSN 1335-2393

[5] Gaduš, J. (2006). Application of optimization methods in the design of agricultural equipment. In HOMIŠIN, J. et al. (2006). Current trends optimization of machinery and equipment. Košice: C-PRESS - Publishing and printing 450 p., ISBN 80-8073-656-1

[6] Suman, B. (2004). Study of simulated annealing next term based algorithms for multiobjective optimization of a constrained problem, Computers \& Chemical Engineering Volume 28, Issue 9, 15 August 2004, p. 1849-1871

[7] FESTO Group CAD models support. (2011). Available from:http://www.festo.com/cms/sk_sk/9541.htm - CAD models, Accessed on: 2011-04-20

[8] FESTO Group Suction grippers (2011) Available from:http://www.festo.com/cat/sk_sk/data/doc engb/PDF/EN/ ESG_EN.PDF - Suction grippers, Accessed on: 2011-04-20 